\section{RSP}

http://www.rsp.fsp.usp.br/
Revista de Saúde Pública

\title{
Primary Health Care: care coordinator in regionalized networks?
}

Patty Fidelis de Almeida', Adriano Maia dos Santos"

' Departamento de Planejamento em Saúde. Instituto de Saúde Coletiva. Universidade Federal Fluminense. Niterói, RJ, Brasil

" Instituto Multidisciplinar em Saúde. Campus Anísio Teixeira. Universidade Federal da Bahia. Vitória da Conquista, BA, Brasil

\section{RESUMO}

OBJECTIVE: To analyze the breadth of care coordination by Primary Health Care in three health regions.

METHODS: This is a quantitative and qualitative case study. Thirty-one semi-structured interviews with municipal, regional and state managers were carried out, besides a cross-sectional survey with the administration of questionnaires to physicians (74), nurses (127), and a representative sample of users (1,590) of Estratégia Saúde da Família (Family Health Strategy) in three municipal centers of health regions in the state of Bahia.

RESULTS: Primary Health Care as first contact of preference faced strong competition from hospital outpatient and emergency services outside the network. Issues related to access to and provision of specialized care were aggravated by dependence on the private sector in the regions, despite progress observed in institutionalizing flows starting out from Primary Health Care. The counter-referral system was deficient and interprofessional communication was scarce, especially concerning services provided by the contracted network.

CONCLUSIONS: Coordination capacity is affected both by the fragmentation of the regional network and intrinsic problems in Primary Health Care, which poorly supported in its essential attributes. Although the health regions have common problems, Primary Health Care remains a subject confined to municipal boundaries.

DESCRIPTORS: Primary Health Care, organization \& administration. Health Services, supply \& distribution. Health Services Coverage. Regional Health Planning. Systems Integration.

Patty Fidelis de Almeida

Rua Marquês de Paraná, $3033^{\circ}$ andar

Prédio Anexo ao Hospital

Antonio Pedro

24030-210 Niterói, RJ, Brasil

E-mail: pattyfidelis@id.uff.br

Received: 7 Aug 2015

Approved: 14 Jan 2016

How to cite: Almeida PF, Santos

AM. Primary Health Care: care

coordinator in regionalized

networks? Rev Saude Publica.

2016;50:80

Copyright: This is an open-access article distributed under the terms of the Creative Commons Attribution License, which permits unrestricted use, distribution, and reproduction in any medium, provided that the original author and source are credited. 


\section{INTRODUCTION}

Lack of care coordination is identified as a major cause of poor quality in health services, associated with higher costs, duplication and overuse of diagnostic procedures, use of multiple medicines, and conflicting therapies, with chronic conditions suffering the greatest negative impact ${ }^{6,12,14, a}$.

Coordination presupposes organizing patient care, which may involve two or more providers and users themselves, in order to facilitate the timely provision of services, involving planning related to staff and other resources and instruments for information exchange between providers ${ }^{13,17}$.

Organizational elements to ensure coordination should include the definition of shared goals for the health system; financial incentives via disbursement and allocation of resources; communication mechanisms between health professionals; development of a common culture and leadership oriented towards teamwork, collaboration and better performance; and strengthening of a care model based on Primary Health Care (PHC) .

Different contexts must be considered, since there is no broadly developed definition ${ }^{13}$. The Política Nacional de Atenção Básica (PNAB - National Primary Care Policy) ${ }^{\mathrm{b}}$ defines coordination as "coordination of integrality," one of the basis of PHC, which should be enabled by means of horizontal integration strategies (programmatic action and spontaneous demand, surveillance and care initiatives, multidisciplinary and interdisciplinary work) and vertical integration strategies between different levels of the Healthcare Networks.

In Brazil, studies suggest that integration of Healthcare Networks, one of the dimensions of coordination, has been strengthened by expansion of Family Health Strategy; creation of specialized services in health districts; introduction of a regulatory system; computerization of medical records; development of management and clinical protocols; and initiatives in communication and technical support ${ }^{1,8,9,15}$.

In this article, care coordination is understood as interaction between various services, actions and professionals related to health care to ensure it is always synchronized and focused on achieving a common goal, regardless of where it is provided ${ }^{11}$. It is supported

a Schang L, Waibel S, Thomson S. Measuring care coordination: health system and patient perspectives: report prepared for the Main Association of Austrian Social Security Institutions. London: LSE Health; 2013 [cited 2015 Jul 5]. Available from: http://eprints. Ise.ac.uk/59573/1/_Ise.ac.uk_ storage_LIBRARY_Secondary_ libfile_shared_repository Content_Schang\%2C\%20 L Schang_Measuring\%20care\%20 coordination_2014.pdf

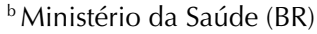
Portaria 2.488, de 21 de outubro de 2011. Aprova a Política Nacional de Atenção Básica, estabelecendo a revisão de diretrizes e normas para a organização da Atenção Básica, para a Estratégia Saúde da Família (ESF) e o Programa de Agentes Comunitários de Saúde (PACS). Brasília (DF); 2011 [cited 2015 Jul 5]. Available from: http://bvsms.saude.gov. br/bvs/saudelegis/gm/2011/ prt2488_21_10_2011.html by the existence of integrated action between providers at different levels or within a same level, so that different interventions are perceived and experienced by users in a manner that is continuous and appropriate to their health needs 5 .

This article sought to examine the breadth of care coordination by PHC in regionalized networks. It aims to contribute new elements by debating the issue in the context of health regions, given the lack of research proposing to investigate coordination in circumstances that require horizontal integration between same-level professionals and services providers, based on PHC with strong essential attributes, and vertical integration between network services managed by different state agencies. Therefore, analyzing facilitating devices and barriers to coordination in regional areas may indicate paths to achieve timelier and higher quality access to the Brazilian Unified Health System (SUS).

\section{METHODS}

This is a case study carried out in three municipal centers of the health regions of Feira de Santana, Santo Antônio de Jesus and Vitória da Conquista, in the state of Bahia. It combined qualitative and quantitative approaches - "mixed methods"10, using semi-structured interviews and surveys.

The qualitative analysis was performed based on 31 semi-structured interviews with managers at municipal, state and regional level, in 2012. 
The experiences of professionals were assessed based on self-administered questionnaires with physicians and nurses of Equipes de Saúde da Família (EqSF - Family Health Teams) in activity in October 2012: 84 in Feira de Santana, 21 in Santo Antônio de Jesus and 38 in Vitória da Conquista, with estimated population coverage of $51.5 \%, 78.7 \%$ and $41.2 \%$, respectively ${ }^{c}$. Physicians and nurses were chosen because they are more directly involved in coordinating activities. The instrument used was adapted from a study by Giovanella et al. ${ }^{\mathrm{d}}$ (2008). The survey administered 106 questionnaires in Feira de Santana, 31 in Santo Antônio de Jesus, and 64 in Vitória da Conquista, i.e., 201 of the 286 planned questionnaires. Losses (30\%) are unevenly distributed between physicians (48\%) and nurses (11\%), justified not by refusal, but by precarious labor contracts, deteriorated during the period of municipal elections.

A household-based survey was carried out, with a questionnaire administered to a representative sample of families enrolled in EqSF in each municipality. The family respondent was the head of household or spouse, interviewed at home. The questionnaire for users was also adapted from Giovanella et al. ${ }^{\circ}$ Calculation of the users sample considered the percentage of population covered by EqSF ( $p$ ), according to Caderno de Avaliação e Monitoramento da Atenção Básica ${ }^{e}$ (Primary Care Monitoring and Assessment Register), assuming 95\% confidence level $\left(z^{2}\right)$ (represented by the value 1.96, of the normal distribution abscissa $[0.1])$ and $4 \%$ accuracy $(w-\pi)^{2}$. The number of users, assuming a simple random sample, was 596, 430 and 576 for Feira de Santana, Santo Antônio de Jesus and Vitória da Conquista, respectively, for a total sample of 1,602 users.

Users were selected by cluster sampling in three stages. The first selected the number of users to be interviewed in each EqSF, dividing the sample of each municipality by the number of existing teams in October 2012. In the second stage, a community health worker was selected for each EqSF by simple random sampling. Finally, the number of families of the selected community health worker was drawn. The questionnaires for professionals and users were administered between November 2012 and February 2013. For users, 1,590 questionnaires were administered.

The concept of coordination used in the study was operationalized by means of dimensions and indicators that incorporate components to strengthen the essential attributes of PHC, such as organization as first contact of preference and breadth/resolvability; and integration of Healthcare Networks, such as provision of and access to specialized care and communication between professionals (Table 1).

The qualitative results of the semi-structured interviews are presented in narrative synthesis. Data of the different methods were triangulated, seeking to integrate the perspective of managers, professionals and families, in addition to performing a comparative analysis between the cases. Quantitative data were encoded and computed in Epidata, and Epidata Stat was used for descriptive analysis.

The project was approved by the Research Ethics Committee of Faculdade Maria Milza (Opinion 323/2011) and authorized by the Municipal Health Department.

\section{RESULTS}

The results were organized according to dimensions and indicators featured in Table 1, which together represent strategies to achieve better care coordination based on strengthening PHC and integrating Healthcare Networks, based on the results of the cross-sectional study and interviews with managers in the health regions studied.

The organization of PHC as first contact of preference was one of the dimensions used to analyze how to strengthen coordination. The survey with families showed a high percentage of registered users who were aware of ESF, with the lowest rates in Vitória da Conquista. Many of them possibly did not use Unidade de Saúde da Família (USF - Family Health Unit), 
Table 1. Matrix structure for analysis of care coordination by Primary Health Care in Health Regions.

\begin{tabular}{|c|c|}
\hline Dimension & Indicator \\
\hline $\begin{array}{l}\text { Organization of PHC as first } \\
\text { contact of preference }\end{array}$ & $\begin{array}{l}\text { Awareness of ESF }(U) \\
\text { Awareness of and easy access to ESF facility }(\mathrm{U}) \\
\text { Knowledge of and home visit by CHW }(\mathrm{U}) \\
\text { Private health insurance coverage (U) } \\
\text { USF as regularly sought service and first contact (U/P) } \\
\text { Average waiting time for medical appointment at USF (P) } \\
\text { Scheduling medical appointments (U) } \\
\text { Spontaneous demand care (U/P) } \\
\text { Regional strategies to strengthen PHC }(\mathrm{M})\end{array}$ \\
\hline PHC breadth and resolvability & $\begin{array}{l}\text { Strategies to increase PHC breadth and resolvability (techincal support, oral health coverage, physical infrastructure } \\
\text { and facilities, logistics and communication support) }(\mathrm{M}) \\
\text { Availability of physicians }(\mathrm{M}) \\
\text { EqSF professional responsible for care }(\mathrm{U}) \\
\text { Satisfaction with care }(\mathrm{U}) \\
\text { Resolution of health problem in EqSF care }(\mathrm{U} / \mathrm{P}) \\
\text { Actions executed when health problem is not resolved (U) } \\
\text { Sample collection for lab tests at USF }(\mathrm{P}) \\
\text { Performance of clinical pathology tests required by EqSF }(U) \\
\text { Access to medicines prescribed by EqSF (U/P) }\end{array}$ \\
\hline $\begin{array}{l}\text { Provision of and access to } \\
\text { specialized care in Healthcare } \\
\text { Network }\end{array}$ & $\begin{array}{l}\text { Adequate provision of specialized care in } \mathrm{HN}(\mathrm{M}) \\
\text { Provision of specialized care appointments }(\mathrm{U}) \\
\text { Forms of access to specialized care appointments referred by EqSF (U/P/M) } \\
\text { Scheduling of specialized care appointments and tests and hospitalization by EqSF (P) } \\
\text { Performance of specialized lab tests requested by EqSF }(\mathrm{U}) \\
\text { Forms of access to specialized lab tests }(\mathrm{U}) \\
\text { Main characteristic of specialized services }(\mathrm{M}) \\
\text { Regional strategies to provide specialized care }(\mathrm{M})\end{array}$ \\
\hline $\begin{array}{l}\text { Communication between } \\
\text { professionals }\end{array}$ & $\begin{array}{l}\text { Use of referral and counter-referral instruments (P/M) } \\
\text { Computerization of health services }(\mathrm{M}) \\
\text { Use of clinical protocols }(\mathrm{M}) \\
\text { Completion of medical records following appointments at USF (P) } \\
\text { Follow-up care of users of other health services (U/P) }\end{array}$ \\
\hline
\end{tabular}

U: users/families; P: professionals (physicians and nurses) of family health teams; M: health managers; ESF: Family Health Strategy; USF: Family Health Unit; CIR: Comissão Intergestores Regional (Regional Inter-Managerial Commission); CHW: Community Health Worker; EqSF: Equipe de Saúde da Família (Family Health Team); HN: Healthcare Networks

especially among teams with a high number of registered families. In the three municipalities, most users claimed to know where the USF facility was located and considered it easily accessible. The community health worker was known to respondents and a significant percentage reported receiving monthly home visits (Table 2).

The results also indicated significant search for other service modalities as first contact, even at times and days in which USF was open and in contexts of low private health insurance coverage. In Feira de Santana, polyclinics - emergency services operating 24 hours a day with specialists - strongly competed for first contact (Table 2). According to managers, the operation of polyclinics was quite varied: some of them provided initial care and referred users to USF, while others didn't.

In Santo Antônio de Jesus, a regional hospital offering outpatient care by spontaneous demand, not linked to PHC, was routinely sought as first contact of preference, accounting for first contact services on weekdays, according to $33.0 \%$ of users (Table 2). For managers, hospital-centered culture was very strong, with spontaneous demand at the regional hospital consisting of users who firstly visited USF or sometimes didn't even bother to go there, claiming there were no doctors or materials, either at the municipal center or other municipalities of the health region.

In Vitória da Conquista, the excessive number of people under the care of a single EqSF limited the capacity of professionals to meet needs in a resolvable and timely manner. This situation was synthesized by the manager:(...) we see teams that are overcrowded with families. (...). We have been unable to ensure access even to those who seek it, so we have many accesses via emergency care of things that are not urgent."(Municipal Manager/Vitória da Conquista). 
Another reason for users to seek different means of first contact, in the three municipalities, was poor or inexistent reception services, although professionals evaluated that the team incorporated care into meeting spontaneous demand and people seek USF first when they need care (Table 3). The evaluation of users indicates problems in scheduling medical appointments and, especially, in meeting spontaneous demand (Table 2), suggesting problems in the organization of first contact. Overall, the evaluations of professionals were more favorable regarding access conditions to USF, although the average waiting time for an appointment might exceed 15 days, according to $1 / 3$ of professionals in Feira de Santana (Table 3).

Although managers reported similar problems in consolidating PHC in the health region, strategies to face barriers and find solutions were still limited to the municipal level, being off the agenda of regional governance initiatives such as Comissão Intergestores Regional

Table 2. Primary Health Care as first contact of preference according to users and families registered with Family Health Teams (EqSF). Feira de Santana, Santo Antônio de Jesus e Vitória da Conquista, BA, Northeastern Brazil, 2013.

\begin{tabular}{|c|c|c|c|}
\hline \multirow[t]{2}{*}{ Indicator } & $\begin{array}{l}\text { Feira de } \\
\text { Santana }\end{array}$ & $\begin{array}{c}\text { Santo Antônio } \\
\text { de Jesus }\end{array}$ & $\begin{array}{l}\text { Vitória da } \\
\text { Conquista }\end{array}$ \\
\hline & $\%$ & $\%$ & $\%$ \\
\hline Users aware of ESF (spontaneous + prompted) & $97(n=588)$ & $96(n=430)$ & $73(n=572)$ \\
\hline Users aware of ESF facility location & $99(n=572)$ & $96(n=412)$ & $95(n=420)$ \\
\hline Easy access to USF facility & $97(n=565)$ & $95(n=396)$ & $97(n=399)$ \\
\hline Users who reported accessing ESF facility on foot & $95(n=565)$ & $93(n=396)$ & $87(n=399)$ \\
\hline Users who are aware of $\mathrm{CHW}$ & $98(n=572)$ & $96(n=412)$ & $96(n=420)$ \\
\hline Users who have been visited by $\mathrm{CHW}$ & $98(n=560)$ & $92(n=395)$ & $95(n=404)$ \\
\hline Users visited by $\mathrm{CHW}$ at least once a month & $68(n=546)$ & $63(n=363)$ & $68(n=386)$ \\
\hline Families with private health insurance & $22(n=588)$ & $16(n=430)$ & $19(n=572)$ \\
\hline Family members covered by private health insurance & $\mathrm{n}=129$ & $\mathrm{n}=69$ & $\mathrm{n}=106$ \\
\hline One family member & 46 & 43 & 44 \\
\hline Two family members & 18 & 25 & 21 \\
\hline Three or more family members & 17 & 32 & 35 \\
\hline Assessment of users regarding scheduling medical appointments* & $n=443$ & $\mathrm{n}=308$ & $\mathrm{n}=306$ \\
\hline Very good/Good & 68 & 58 & 54 \\
\hline Very poor/Poor & 29 & 35 & 42 \\
\hline $\begin{array}{l}\text { Assessment of users regarding obtaining medical appointments without previous scheduling - } \\
\text { spontaneous demand* }\end{array}$ & $n=443$ & $\mathrm{n}=308$ & $\mathrm{n}=306$ \\
\hline Very good/Good & 42 & 39 & 29 \\
\hline Very poor/Poor & 42 & 50 & 52 \\
\hline Health service sought for illnesses on weekdays & $\mathrm{n}=588$ & $n=430$ & $\mathrm{n}=572$ \\
\hline Family Health Unit & 43 & 49 & 39 \\
\hline Polyclinic & 36 & 0 & 0 \\
\hline Public hospital outpatient/Emergency service & 6 & 33 & 37 \\
\hline Clinic/Private hospital or emergency service & 5 & 6 & 8 \\
\hline Private consultation & 2 & 5 & 5 \\
\hline Other & 8 & 7 & 11 \\
\hline Health service sought for illnesses on weekends/holidays/nighttime & $\mathrm{n}=588$ & $\mathrm{n}=430$ & $\mathrm{n}=572$ \\
\hline Family Health Unit & 0.3 & 0 & 4 \\
\hline Polyclinic & 71 & 0 & 0 \\
\hline Public hospital outpatient/Emergency service & 13 & 83 & 68 \\
\hline Clinic/Private hospital or emergency service & 6 & 6 & 10 \\
\hline Private consultation & 1.7 & 4 & 4 \\
\hline Other & 8 & 7 & 14 \\
\hline
\end{tabular}

ESF: Family Health Strategy; USF: Family Health Unit; CHW: Community Health Worker $\mathrm{n}=$ total number of respondents

* Users who reported having received care at a Family Health Unit in the previous 12 months. 
Table 3. Primary Health Care (PHC) organization as first contact of preference, breadth and resolvability, provision of and access to specialized care, and communication between professionals according to physicians and nurses of Family Health Team (EqSF). Feira de Santana, Santo Antônio de Jesus e Vitória da Conquista, BA, Northeastern Brazil, 2013.

\begin{tabular}{|c|c|c|c|}
\hline \multirow[t]{2}{*}{ Indicator } & $\begin{array}{l}\text { Feira de } \\
\text { Santana }^{a}\end{array}$ & $\begin{array}{c}\begin{array}{c}\text { Santo Antônio } \\
\text { de Jesus }{ }^{b}\end{array} \\
\end{array}$ & $\begin{array}{c}\text { Vitória da } \\
\text { Conquista }^{c}\end{array}$ \\
\hline & $\%$ & $\%$ & $\%$ \\
\hline \multicolumn{4}{|l|}{ PHC organization as first contact of preference } \\
\hline Completely agree/agree that the population first seeks USF for health care & 92 & 77 & 91 \\
\hline Completely agree/agree that with ESF the population seeks fewer hospital and specialized services & 81 & 74 & 84 \\
\hline Completely agree/agree that the population first seeks the hospital or emergency network for health care & 19 & 10 & 19 \\
\hline Completely agree/agree that USF only provides care with previous scheduling & 10 & 6 & 6 \\
\hline Completely agree/agree that USF provides care for spontaneous demand & 88 & 97 & 98 \\
\hline Completely agree/agree that the average waiting time for a medical appointment at USF exceeds 15 days & 33 & 16 & 19 \\
\hline \multicolumn{4}{|l|}{ PHC breadth and resolvability } \\
\hline Evaluate as very satisfactory/Satisfactory the capacity of EqSF to solve $80 \%$ or more of cases treated at USF & 89 & 77 & 78 \\
\hline Provision of sample collection for lab tests at USF & 9 & 77 & 66 \\
\hline Evaluate as very satisfactory/Satisfactory the regular distribution of medicines by the team & 69 & 84 & 75 \\
\hline \multicolumn{4}{|l|}{ Provision of and access to specialized care in Healthcare Network (HN) } \\
\hline \multicolumn{4}{|l|}{ Most common pathway for patients from care at UBS to referral to specialized care } \\
\hline The appointment is scheduled by UBS and the date is later informed to patient & 60 & 48 & 94 \\
\hline The patient leaves UBS with a scheduled appointment & 25 & 6 & 0 \\
\hline \multicolumn{4}{|l|}{ Patients are always/Most times able to schedule other services } \\
\hline Appointment with specialists & 75 & 61 & 63 \\
\hline Specialized test & 76 & 55 & 75 \\
\hline Hospitalization & 58 & 48 & 64 \\
\hline \multicolumn{4}{|l|}{ Communication between professionals } \\
\hline Report completing medical record after each consultation & 94 & 100 & 98 \\
\hline Always/Most times provide written information when patients are referred to other services & 92 & 90 & 83 \\
\hline Always/Most times receive counter-referral following user's consultation with a specialist & 13 & 10 & 5 \\
\hline Completely agree/Agree that physicians are able to provide follow-up care for users of other health services & 33 & 42 & 56 \\
\hline Completely agree/Agree that nurses are able to provide follow-up care for users of other health services & 50 & 61 & 64 \\
\hline
\end{tabular}

ESF: Family Health Strategy; USF: Family Health Unit; HN: Healthcare Networks; UBS: Unidade Básica de Saúde (Basic Health Unit)

a 36 physicians and 70 nurses.

b 10 physicians and 21 nurses.

c 28 physicians and 36 nurses.

(Regional Inter-Managerial Commission). This was confirmed in the interviews, in which managers explained they could only account for PHC dynamics in their own municipality.

PHC breadth and resolvability are important dimensions of care coordination. In Feira de Santana, according to managers, these elements were compromised by factors such as: insufficient number of Núcleos de Apoio à Saúde da Familia (NASF - Centers for Family Health Support), lack of oral health teams in all USF, reduced or simplified offer of health actions, few community interventions, low involvement of doctors in collective and administrative actions, and poor logistics and communications support for integration. Interviews indicated scarce and irregular supply of inputs and inadequate physical infrastructure and facilities in many USF.

In Vitória da Conquista, managers stressed the participation of professionals in offering technical and pedagogical support to EqSF as an alternative to the physician-centered view. It was emphasized that this is a recent experience in the health region, with insufficient numbers of NASF to meet the demands of EqSF, similar to the reality of Feira de Santana.

In the three regions, according to managers, attraction and retention of physicians generated distortions, influencing care quality and resolvability. Managers mentioned they were unable 
to select professionals with the necessary profile to work in ESF, and frequently "turned a blind eye" to absences and carelessness, with physicians often being "auctioned" among the region's cities. However, they reported no effort to seek regional solutions to the problem.

Nonetheless, the results of the present study showed that physicians were responsible for the care of most users seeking USF. When asked about satisfaction concerning consultations with physicians, the majority (> 69\%) reported being "very satisfied/satisfied" (Table 4).

Users in the three municipalities reported positively on having their problem resolved at USF (> 70\%) (Table 4), similar to the evaluation by professionals (Table 3).

The survey with families indicated that even when they could not access a service or have their problems solved at ESF, in all three cases most people (50\% to 62\%) sought public services. However, an important percentage of the population sought care from the private sector (23\% to $33 \%)$ (Table 4$)$.

In Feira de Santana, samples for lab tests were not collected at USF, which was confirmed by professionals (Table 3). In turn, polyclinics collected biological samples, which prompted demand for their services. In Santo Antônio de Jesus and Vitória da Conquista, according to managers, test samples were collected at USF, including rural areas.

Among families that required lab tests requested by EqSF in the previous 12 months, $76 \%, 85 \%$ and $92 \%$, respectively, in Santo Antônio de Jesus, Feira de Santana and Vitória da Conquista, reported being able to do them; however, between $52 \%$ and $67 \%$ of that total reported that all tests were done in the public network, with the best service offered in Vitória da Conquista. Between $14 \%$ and $26 \%$ of users reported doing tests in the private network, and about $1 / 4$ were unable to do the prescribed test, especially in Feira de Santana (Table 4).

Among users served by EqSF, $85 \%$ to $91 \%$ required medicines in the three cases studied. Most (50\% to 64\%) reported receiving only a few (Table 4), but a significant percentage, around 40\% in Santo Antônio de Jesus and Feira de Santana, received all medicines from SUS. Professionals, especially those working in Santo Antônio de Jesus, evaluated positively the regular distribution of medicines (Table 3 ).

Regarding the provision of and access to specialized care in Healthcare Networks, an essential dimension of coordination, in the three municipal centers of the health regions, managers pointed out that provision of procedures for therapeutic support and financial resources for their expansion were insufficient. Therefore, they had to cope with the short supply, compromising health requirements and generating ethical conflicts between the EqSF, since they had to, among the numerous needs, choose which users had "priority."

Access to more complex technological services, in all three cases, mainly occurred via referral by PHC, according to managers. When the procedure was scheduled, the referral form usually returned to EqSF; therefore, users then returned to USF or were contacted by the community health worker (Tables 3 and 5). In Santo Antônio de Jesus, a significant percentage (29\%) contacted the scheduling center directly (Table 5).

In the three cases studied, most specialists were professionals with experience in the private sector. In Feira de Santana, there was no specialties center concentrating services, and therefore specialists hired by public notice could work in their private clinics, basic health units or polyclinics. In Santo Antônio de Jesus and Vitória da Conquista, specialized services were hired by public tender, with common non-attendance of providers.

Besides the provision of care to the municipal center, services were procured to meet the needs of the health region's Programação Pactuada e Integrada (Agreed and Integrated Program), which was not always possible based on regulated SUS prices. Often municipalities received a lower quota than agreed on, depending on what they managed to "negotiate" with private providers. For managers, the heavy reliance on the private sector represented an obstacle: "(...) we live in a capitalist world, and must work with SUS, which is a completely 
Table 4. Primary Health Care breadth and resolvability according to users and families registered with Family Health Team (EqSF). Feira de Santana, Santo Antônio de Jesus e Vitória da Conquista, BA, Northeastern Brazil, 2013.

\begin{tabular}{|c|c|c|c|}
\hline \multirow{2}{*}{ Indicator } & Feira de Santana & Santo Antônio de Jesus & Vitória da Conquista \\
\hline & $\%$ & $\%$ & $\%$ \\
\hline EqSF professional responsible for care ${ }^{a}$ & $n=541$ & $\mathrm{n}=391$ & $\mathrm{n}=397$ \\
\hline Physician & 90 & 83 & 88 \\
\hline Nurse & 8 & 13 & 8 \\
\hline Other/Doesn't know/Did not answer & 2 & 4 & 4 \\
\hline Satisfaction with care by physician & $n=486$ & $\mathrm{n}=323$ & $\mathrm{n}=350$ \\
\hline Very satisfied/Satisfied & 81 & 69 & 83 \\
\hline Fair & 15 & 21 & 13 \\
\hline Very dissatisfied/Dissatisfied & 4 & 10 & 3 \\
\hline Doesn't know/Did not answer & 0 & 0 & 1 \\
\hline Health problem solved by EqSF care ${ }^{a}$ & $n=541$ & $\mathrm{n}=391$ & $\mathrm{n}=397$ \\
\hline Yes & 83 & 70 & 78 \\
\hline No & 17 & 30 & 22 \\
\hline Action taken when health problem is not solved & $\mathrm{n}=91$ & $\mathrm{n}=117$ & $\mathrm{n}=87$ \\
\hline Referral to public network specialist by EqSF & 25 & 20 & 29 \\
\hline Direct search for care in public hospitals/emergency services & 37 & 30 & 26 \\
\hline Direct search for care in private health network & 23 & 33 & 24 \\
\hline No action taken/No search for health services & 6 & 14 & 8 \\
\hline Other/Doesn't know/Did not answer & 9 & 3 & 13 \\
\hline Performance of clinical pathology tests requested by EqSF professional ${ }^{b}$ & $\mathrm{n}=280$ & $\mathrm{n}=141$ & $\mathrm{n}=207$ \\
\hline All tests performed in the public network & 58 & 52 & 67 \\
\hline Some tests performed in the public network & 16 & 26 & 19 \\
\hline All tests performed in the private network & 26 & 22 & 14 \\
\hline Access to medicines prescribed by $\mathrm{EqSF}^{c}$ & $\mathrm{n}=461$ & $\mathrm{n}=341$ & $n=360$ \\
\hline Received all medicines & 40 & 43 & 31 \\
\hline Received some medicines & 53 & 50 & 64 \\
\hline Did not receive any medicines & 7 & 7 & 5 \\
\hline
\end{tabular}

$\mathrm{n}=$ Total number of respondents

a Users who reported having received care at a Family Health Unit.

${ }^{\mathrm{b}}$ Families that reported having done clinical pathology tests requested by Family Health Team (EqSF) in the previous 12 months.

c Families that reported having needed medicines prescribed by Family Health Team (EqSF) in the previous 12 months.

non-capitalist model; making this system work depending on the private sector, that generates conflict"(state manager).

The purchase of specialized services within the logic of procurement procedures was also mentioned by managers as a factor that undermines the possibility of building an integrated network and care coordination via PHC: "It is fragmented from the start..." (municipal manager/Santo Antônio de Jesus).

Queues and long waiting times for specialized care were common situations in all three cases. Requests for tests or procedures without protocols or well-defined criteria intensified problems in the regions. In Feira de Santana, private sector doctors could request "high complexity" tests, which were authorized by the scheduling center, competing with SUS users. Setting up task forces was a strategy to minimize waiting times in the three municipal centers.

For managers, expanding services was not sufficient, since there were no specialists available in the inland areas of Bahia. They emphasized that care gaps varied widely in the state, although advances were mentioned with the building of regional hospitals.

The difficulties in providing specialized care are reflected in the assessment of users. In all three cases, about half of those who were aware of ESF reported having needed to consult a 
specialist in the previous 12 months. Of those, $44 \%$ to $51 \%$ sought treatment in the private sector, commonly without referral by EqSF. In Feira de Santana and Santo Antônio de Jesus, $11 \%$ and $9 \%$ of users, respectively, sought private care, even with referral by EqSF (Table 5). About $2 / 3$ of professionals reported they were able to schedule appointments with specialists "always or most times." In all three cases, greater difficulties were observed in relation to scheduling hospitalization, according to professionals (Table 3). Only Vitória da Conquista had its own central service to regulate hospital beds and admissions.

Part of users who were aware of ESF ( $31 \%$ to $43 \%$ ) reported the need for specialized tests in the previous 12 months. Of those who did the tests, most users in Feira de Santana (72\%) and Vitória da Conquista (85\%) stated that they were scheduled by EqSF.

The development of thematic networks (care lines) was seen as an advance in creating regionalized networks and overcoming fragmentation. Thematic networks would be a resource for creating a state plan for regional health care, according to state managers.

Regarding communication between professionals in the network, the last dimension of coordination to be analyzed, managers said the system of counter-referral was deficient, further worsened when services were provided by the contracted network.

Table 5. Provision of and access to specialized care in Healthcare Networks and communication between professionals according to registered users and families. Feira de Santana, Santo Antônio de Jesus e Vitória da Conquista, BA, Northeastern Brazil, 2013.

\begin{tabular}{|c|c|c|c|}
\hline \multirow{2}{*}{ Indicator } & Feira de Santana & Santo Antônio de Jesus & Vitória da Conquista \\
\hline & $\%$ & $\%$ & $\%$ \\
\hline Reported having seen a specialist in the previous 12 months & $51(n=572)$ & $51.5(n=412)$ & $55(n=420)$ \\
\hline Service providing consultation with specialist & $\mathrm{n}=292$ & $\mathrm{n}=212$ & $\mathrm{n}=232$ \\
\hline Polyclinic & 17 & 17 & 18 \\
\hline Public hospital outpatient care & 15 & 9 & 14 \\
\hline Public hospital & 12 & 16 & 18 \\
\hline Private health service (doctor's office/hospital) & 45 & 51 & 44 \\
\hline Other & 11 & 7 & 6 \\
\hline Specialized appointment referred by EqSF & $47(n=292)$ & $31(n=212)$ & $40(n=232)$ \\
\hline Forms of access to specialized appointment referred by EqSF professional* & $\mathrm{n}=136$ & $\mathrm{n}=65$ & $\mathrm{n}=92$ \\
\hline Scheduled by USF and date and time informed later & 64 & 46 & 71 \\
\hline Scheduled by USF and date and time informed immediately & 4 & 2 & 13 \\
\hline Referral and appointment information received directly at Scheduling Center & 0 & 29 & 4 \\
\hline Referral received, but health service sought independently & 7 & 6 & 1 \\
\hline Referral received, but health service sought and paid for independently & 11 & 9 & 3 \\
\hline Other & 14 & 8 & 8 \\
\hline $\begin{array}{l}\text { Reported having needed to do a specialized test requested by EqSF in the previous } \\
12 \text { months }\end{array}$ & $43(n=572)$ & $31(n=412)$ & $33(n=420)$ \\
\hline Performance of specialized test requested by EqSF & $83(n=248)$ & $59(n=126)$ & $81(n=137)$ \\
\hline Forms of access to specialized test & $\mathrm{n}=206$ & $\mathrm{n}=74$ & $\mathrm{n}=111$ \\
\hline Scheduled by USF and date and time informed later & 69 & 34 & 75 \\
\hline Scheduled by USF and date and time informed immediately & 3 & 5 & 10 \\
\hline Referral and appointment information received directly at Scheduling Center & 0 & 24 & 1 \\
\hline Referral received, but health service sought and paid for independently & 16 & 18 & 2 \\
\hline Other/Unable to inform & 12 & 19 & 12 \\
\hline $\begin{array}{l}\text { Families with hospitalization in the previous } 12 \text { months that received written } \\
\text { post-discharge information for EqSF }\end{array}$ & $24(n=78)$ & $43(n=67)$ & $17.5(n=80)$ \\
\hline $\begin{array}{l}\text { Families with hospitalization in the previous } 12 \text { months who reported requesting } \\
\text { information or visit by a EqSF professional during hospitalization }\end{array}$ & $35(\mathrm{n}=78)$ & $40(n=67)$ & $27.5(n=80)$ \\
\hline $\begin{array}{l}\text { Professional responsible for seeking information or visiting patient during } \\
\text { hospitalization - CHW }\end{array}$ & $63(\mathrm{n}=27)$ & $67(\mathrm{n}=27)$ & $73(\mathrm{n}=22)$ \\
\hline
\end{tabular}

EqSF: Equipe de Saúde da Família (Family Health Team); USF: Family Health Unit; HN: Healthcare Networks; CHW: Community Health Worker $\mathrm{n}=$ total number of potential respondents.

* Users referred by EqSF who reported having seen a specialist. 
Counter-referral only occurred at the request or demand of the actual user. Referral was an instrument for scheduling procedures, and not of interprofessional communication. The survey with professionals showed that only 5\% to $13 \%$ reported receiving counter-referrals frequently (Table 3 ).

Computerization of USF was partial and, if any, limited to scheduling appointments, and never used as a communication flow instrument. In Feira de Santana, the existence of electronic medical records was reported in some units, although they were not shared with the other network services. According to managers, implementation of clinical protocols was incipient.

In Santo Antônio de Jesus, about 43\% of households reported receiving post-discharge information, and $40 \%$ reported requesting information or visits by EqSF professionals during hospitalization, especially community health workers (Table 5). For professionals, there were difficulties in follow-up care for users of services outside PHC (Table 3).

\section{DISCUSSION}

The four dimensions investigated point to limits that endanger regional care coordinated by PHC. In this same perspective, Fausto et al. ${ }^{8}$ reaffirm that coordination by PHC depends on timely and resolvable first contact, attention to and care of spontaneous demand, comprehensive provision of services, and technical support. In the cases studied, the role of first contact of preference faces strong competition from hospital outpatient and emergency care services, outside the network, often devised to meet the demand for specialized care, such as regional hospitals. This situation is aggravated by problems of work organization in PHC, with disparity between programmed actions and spontaneous demand, barriers also identified by other studies ${ }^{2,89}$, and excessive number of users per EqSF.

There is need to expand clinical nursing actions, Centers for Family Health Support, and oral health as measures that could help people recognize that EqSF is not restricted to physicians. The study also points to the need to strengthen $\mathrm{PHC}$ by the regular provision of medicines and other inputs. Despite the constraints, PHC, in the perception of users and professionals, seems to have good resolvability, which reaffirms the need for investments to enhance it. The indistinct search for public services as first contact, whether USF, polyclinics or hospitals, demonstrates the need to organize and coordinate services offered by the network, so that access via $\mathrm{PHC}$ is preferred.

In all three cases, users expand their options as services are increasingly fragmented and coordination is dispersed. Cecilio et al. ${ }^{7}$ show that although users value USF, they multiply their possibilities by combining expected $\mathrm{PHC}$ resources with other services on the network. When coordination is extrapolated to health regions, the role of EqSF dissipates, for several reasons. Provision of specialized services is highly dependent on the private sector, whose public insufficiency and underfunding, combined with occasional inadequate use, can be identified as factors that hinder the establishment of regional networks. In addition, the selected health regions have historical care deficit, difficulty in attracting and offering certain specialties, physicians disinterested in the civil service (due to precarious labor relations in SUS), and high bargaining power of some specialties. Such problems go beyond the management capacity of isolated municipalities, requiring a shared stance ${ }^{15}$.

Although access to specialties via $\mathrm{PHC}$ in the health region has been formally organized, the incorporation of specialists by procurement of procedures accentuates fragmentation and weakens the mechanisms of care coordination and regulation. While large municipalities prioritize the establishment of local specialized services ${ }^{1}$, in the context of health regions there seems to be a pressing need for other ways of incorporating therapeutic support, in a perspective of intercity networks. In this sense, initiatives such as Comissão Intergestores Regional (Regional Inter-Managerial Commission) need to be strengthened and recognized as 
means of joint regional governance, able to overcome the municipal logic, which is ineffective to build regional networks for comprehensive care. To this end, Regional Intermanagers Commission (CIR) should bring together strategies for managers to establish joint health agreements to enhance the provision of public services, overcoming the fragile contract mechanisms with the private sector, since there is no proper monitoring of agreed goals among private providers, other than post factum auditing. In general terms, there is a relationship of mutual dependence between the public and private sectors; however, private contractors providing services to SUS have gained the upper hand, defining market prices for procedures and services to the detriment of public interest.

The need for communication between professionals and providers to achieve better care coordination is a consensus ${ }^{5,13, a}$. Coordination actions will likely fail under the sole responsibility of physicians ${ }^{4}$. In this study, for example, the community health worker was responsible for seeking information and visiting patients during hospitalization, indicating potential ways to maximize action horizontal coordination.

Unforeseen findings of this study, which nevertheless are relevant to the analyzed subject, include the absence of physicians at USF during data collection, carried out before and during the municipal elections. Physicians accounted for a greater percentage of losses, especially because of the absence or sporadic presence of these professionals at USF. Even though the election campaign may have generated instability and increased the precariousness of labor relations, especially in Feira de Santana and Santo Antônio de Jesus, turnover was higher among physicians, especially due to their greater employability and possibility of establishing new links in other municipalities. The losses are revealing of a concrete situation also experienced by users, influencing difficulty of access and timely care, leading to the search for emergency care services and, ultimately, thwarting care coordination by PHC.

The constraints of PHC coordination are varied, comprising a set of services that do not compose an integrated network with a view to coordinating subjects, knowledge and practices ${ }^{3}$, and lack of strong PHC essential attributes, requiring initiatives that go beyond municipal boundaries to organize the health care network within health regions.

Nevertheless, it is clear that the success of the health regions studied requires the fulfillment of responsibilities among managers of different entities who, despite the normative expectations of regionalization, are unable to agree on a plan capable of taking the health territory beyond a bureaucratic and programmatic vision. The three regions indicate that, regarding care coordination, there is urgent need for expansion and qualification of first contact services via PHC due to persisting problems of fragmentation and disorderly search for services provided without adequate care regulation.

The health regions indicate a shift from decentralization and a path to enable care integration ${ }^{16}$. However, this study shows that coordination, when it occurs, is limited to the municipal centers of the health regions, i.e., as the vast majority of municipalities need services offered by other entities, care coordination via PHC becomes unfeasible, losing itself in the bureaucratic flow of scheduling centers. Thus, even if a wide offer of services is achieved in a given territory, coordination is an essential attribute to enable continuous care and integrated services, requiring, more than ever, a strong PHC base.

\section{REFERENCES}

1. Almeida PF, Giovanella L, Mendonça MHM, Escorel S. Desafios à coordenação dos cuidados em saúde: estratégias de integração entre níveis assistenciais em grandes centros urbanos. Cad Saude Publica. 2010;26(2):286-98. DOI:10.1590/S0102-311X2010000200008

2. Almeida PF, Giovanella L, Nunan BA. Coordenação dos cuidados em saúde pela atenção primária à saúde e suas implicações para a satisfação dos usuários. Saude Debate. 2012;36(94):375-91. DOI:10.1590/S0103-11042012000300010 
3. Ayres JRCM. Cuidado: trabalho e interação nas práticas de saúde. Rio de Janeiro: Abrasco; 2009 [citado 2015 abr 9]. (Coleção Clássicos para Integralidade em Saúde). Disponível em: http://www.cepesc.org.br/wp-content/uploads/2013/08/miolo-livro-ricardo.pdf

4. Bodenheimer T. Coordinating care: a perilous journey through the health care system. N Eng/ J Med. 2008;358(10):1064-71. DOI:10.1056/NEJMhpr0706165

5. Boerma WGW. Coordenação e integração em atenção primária europeia. In: Saltman RB, Rico A, Boerma WGW, organizadores. Atenção Primária conduzindo as redes de atenção à saúde: reforma organizacional na atenção primária europeia. Berkshire: Open University Press; 2010. p.25-47.

6. Bynum JPW, Ross JS. A measure of care coordination? J Gen Intern Med. 2012;28(3):336-8. DOI:10.1007/s11606-012-2269-0

7. Cecilio LCO, Andreazza R, Carapinheiro G, Araújo EC, Oliveira LA, Andrade MGG, et al. A Atenção Básica à Saúde e a construção das redes temáticas de saúde: qual pode ser o seu papel? Cienc Saude Coletiva. 2012;17(11):2893-902. DOI:10.1590/S1413-81232012001100006

8. Fausto MCR, Giovanella L, Mendonça MHM, Seidl H, Gagno J. A posição da Estratégia Saúde da Família na rede de atenção à saúde na perspectiva das equipes e usuários participantes do PMAQ-AB. Saude Debate. 2014;38 N. Espec:13-33. DOI:10.5935/0103-1104.2014S003

9. Giovanella L, Mendonça MHM, Almeida PF, Escorel S, Senna MCM, Fausto MCR, et al. Saúde da família: limites e possibilidades para uma abordagem integral de atenção primária à saúde no Brasil. Cienc Saude Coletiva. 2009;14(3):783-94. DOI:10.1590/S1413-81232009000300014

10. Greene JC. Mixed methods in social inquiry. San Francisco: John Wiley; 2007.

11. Hofmarcher MM, Oxley H, Rusticelli E. Improved health system performance through better care coordination. Paris: OECD; 2007. (OECD Health Working Papers, No. 30).

12. Kringos DS, Boerma WGW, Hutchinson A, Zee J, Groenewegen PP. The breadth of primary care: a systematic literature review of its core dimensions. BMC Health Serv Res. 2010;10:65 DOI:10.1186/1472-6963-10-65

13. McDonald KM, Schultz E, Albin L, Pineda N, Lonhart J, Sundaram V, et al. Care Coordination Atlas Version 4. Rockville, MD: Agency for Healthcare Research and Quality; 2014. (AHRQ Publication, N.14-0037-EF).

14. Nolte E, McKee M, editors. Caring for people with chronic conditions: a health system perspective. Berkshire: Open University Press; 2008. Integration and chronic care: a review; p. 64-91.

15. Santos AM, Giovanella L. Governança regional: estratégias e disputas para gestão em saúde. Rev Saude Publica. 2014;48(4):622-31. DOI:10.1590/S0034-8910.2014048005045

16. Santos L, Campos GWS. SUS Brasil: a região de saúde como caminho. Saude Soc. 2015;24(2):438-46. DOI:10.1590/S0104-12902015000200004

17. Terraza Núñez R, Vargas Lorenzo I, Vásquez Navarrete ML. La coordinación entre niveles asistenciales: una sistematización de sus instrumentos y medidas. Gac Sanit. 2006;20(6):485-95.

Funding: Conselho Nacional de Desenvolvimento Científico e Tecnológico (CNPq), Edital Universal 14/2011 (Process 479451/2011-7).

Authors' Contributions: PFA and AMS participated equally in design, manuscript draft, data interpretation, and critical review.

Conflict of Interest: The authors declare no conflict of interest. 